\title{
Examining the Attributes of Electronic Waste Recycling Service: A Choice Modelling Approach
}

\author{
Nazatul Faizah Haron ${ }^{1}$, Shaufique F. Sidique ${ }^{2} \&$ Alias Radam $^{3}$ \\ ${ }^{1}$ Department of Economics, Faculty of Economics and Management Sciences, Universiti Sultan Zainal Abidin, \\ Gong Badak Campus, Kuala Nerus, Terengganu Darul Iman, Malaysia \\ ${ }^{2}$ Department of Economics, Faculty of Economics and Management, Universiti Putra Malaysia, Serdang, \\ Selangor, Malaysia \\ ${ }^{3}$ Department of Management and Marketing, Faculty of Economics and Management, Universiti Putra Malaysia, \\ Serdang, Selangor, Malaysia \\ Correspondence: Nazatul Faizah Haron, Department of Economics, Faculty of Economics and Management \\ Sciences, Universiti Sultan Zainal Abidin, Gong Badak Campus, 21300 Kuala Nerus, Terengganu Darul Iman, \\ Malaysia. Tel: 60-19-270-1504. E-mail: nazatulfaizah@unisza.edu.my
}

\author{
Received: December 5, 2016 \\ Accepted: January 4, 2017 \\ Online Published: July 25, 2017 \\ doi:10.5539/ass.v13n8p12 \\ URL: https://doi.org/10.5539/ass.v13n8p12
}

\begin{abstract}
This paper estimates the economic valuation, discusses preferences for electronic waste (e-waste) recycling, and identifies the most preferred attributes in e-waste recycling. Stratified random sampling from the households in Putrajaya, Malaysia was utilised to obtain the primary data. It provides the readers with an intrinsic satisfaction when choosing a modelling analysis on the valuation of non-market goods using conditional logit simple model. The findings indicate that the option attributes were highly significant and there was no inherent bias towards either the change or no-change option held by the respondents.
\end{abstract}

Keywords: choice modelling, recycling, e-waste, non-market goods

\section{Introduction}

Informal electronic waste (e-waste) recycling is a $21^{\text {st }}$ century challenge in the environmental field towards the development of a nation. It appears ambiguously in generating electrical and electronic equipment waste. E-waste is one of the production resources as it contains a lot of valuable components or materials. However, e-waste is dangerous and harmful to the ecosystem and human health if the hazardous substances used are not treated to be environmentally safe. The increasing amount of e-waste (due to the increasing consumption of electrical and electronic equipment) has attracted a lot of attention in the developed countries, especially with regards to issues of e-waste management.

Nowadays, e-waste is perceived as a valuable source of raw material for many industries, and viewed as a good business opportunity if it is supported by proper recycling methods and technologies to safeguard the environment. Waste of electronic equipment has great potential as a valuable resource if it is disposed of responsibly, with the materials reused or recycled to the greatest extent possible. In this case, in terms of the potential to enhance the commercial aspect of e-waste, it is deduced that e-waste is a precious resource with more efficient use and more extensive reuse of materials. It reduces the need to extract more raw materials from the ground as well as reduces environmental effects.

Unlike most forms of municipal solid waste, e-waste has a high value added in every single unit of dumping due to the precious metals contained in the e-waste such as gold, silver, platinum, palladium, and copper (Bleiwas \& Kelly, 2001). The only way to preserve all these valuable materials is through "recycling", which has now emerged as one of the economic potentials with significant impacts on job creation, resource conservation, and provision of economic opportunity. Also, income can be generated through a well-planned recycling program and it also helps in saving enormous amounts of energy and natural resources (Batool, Chaundhry, \& Majeed, 2008).

Next, the United States Environmental Protection Agency (2005) reported that approximately one million manufacturing jobs and US\$100 billion in revenue were generated in the USA through recycling and 
remanufacturing industries (Agarwal et al., 2005). This shows that recycling has strong potential to grow as a sustainable business. As mentioned earlier, recycling is appealing because it offers a way to reduce the amount of waste disposal in landfills and simultaneously save natural resources. Government, businesses, and the public have jointly made strenuous efforts to recycle starting from the late 1980s until today. Consequently, the environmental awareness has started to grow, where the public is focused on recycling as a primary way to protect the environment.

In Malaysia, public awareness towards recycling, especially in e-waste, still leaves much to be desired, although aggressive campaigns towards a greener environment were carried out by the federal and state governments. However, the 3R (Reduce, Reuse, and Recycle) campaign for example, could only be effective through education, which takes years to be perceived as successful. Therefore, active steps must be taken as soon as possible to solve this problem, for example by designing more appropriate recycling programs.

Recycling is a crucial part of the waste management strategies implemented by the public and private sectors due to increasing pressures from the economic, environmental, and political aspects. Recycling programs are different across communities, businesses, and institutions, but most do share some common attributes. The common attributes basically consist of the materials to be recycled, the designs and types of recycling receptacles, the locations of collection sites, as well as the processes and procedures for material separation. Designing effective recycling programs should include an understanding of people's attitudes, recycling behaviours, and their preferences of that program. The designs would impact the size and distribution of factors like separation cost, collection cost, and operational cost, as well as the potential revenues generated from the recycled materials.

Previous studies have discussed the assessment from the perspective of economics and mainly focused on solid waste management, processes, cost-benefit analysis, and business potential in recycling (Batool et al., 2008; Brekke et al., 2003; Liu et al., 2009; Pickin, 2008). Nonetheless, although there have been several studies which looked at the behaviour of e-waste recycling, only a few focused on the attributes of facilities of the e-waste household collection. This paper addresses this gap by examining and conducting trade-off analysis of the potential recycling program, given that the level of recycling in Putrajaya was only $12.5 \%$ in $2011^{1}$ and the e-waste collection rate was still low compared to other materials. This study evaluates recycling service attributes in Putrajaya as part of efforts to develop a new recycling program to increase the e-waste recycling level and build new recycling facilities in the future.

\section{Literature Review}

Electrical and electronic waste (e-waste) components are rapidly changing. Obsolete computers, televisions, cellular phones, and many other outdated electronics, all known as e-waste, are forming a greater proportion of the global waste stream. As technological innovation continues to improve, the lifespan of electronic goods will remain short and the amount of electronic waste that accumulates will continue to rapidly increase. Large-scale dumping of e-waste will pose a problem to the environment because it has the potential to release dangerous substances, which exposure may bring severely harmful effects on human health (Misra \& Pandey, 2005). Due to this, governments around the world are taking various approaches to solve the problem of e-waste disposal. One of the solutions to prevent e-waste from landfill disposal is recycling, which, from the perspective of economics, does have commercial potential (Batool, Chaudhry \& Majeed, 2008).

There is extensive literature available on recycling, which discusses municipal and regional recycling practices that have been associated with improved recycling program performance, participation, and the economics of recycling (Folz, 1991; Timlett \& William, 2008; Bohm et al., 2010). Past researchers noted that the level of recycling activities may improve by increasing community members' knowledge of recycling, the availability of recycling facilities, and community recycling options as well as by making it very convenient and easy to recycle e-waste (Folz, 1991). It was also observed that the duration of the recycling program has a positive impact that may increase households' frequency of recycling. Meanwhile, decentralised recycling programs, which can be successfully carried out with sufficient financial resources, are found to encourage higher participation in recycling activities (Jenkins et al., 2003; Suttibak \& Nitivattananon, 2008).

Narrowing the focus to valuation studies on recycling programs, previous researchers have closely looked at curbside recycling programs (Wilson \& Williams, 2007; Chowdhury, 2009; Caplan et al., 2002) as well as drop-off recycling programs (Sidique et al., 2010; Tiller et al., 1997). The valuation studies mainly focused on waste stream created from households, with survey research conducted to examine household responses. Apart

\footnotetext{
${ }^{1}$ Source: Perbadanan Putrajaya
} 
from that, institutions and companies also have paramount waste stream management concerns that need to be properly addressed. This study seeks to examine and evaluate recycling program preferences among community members in Putrajaya who connect with each other and share the characteristics of a corporation, a small community, and a public entity.

Examining recycling program preferences at the household level has certain advantages, where the data gathered can be used as reference to implement recycling programs at the national level. Investigation of waste coming from households can indicate the need to appeal to consumers to join recycling and reduce waste. Usually, waste management will be handled by the stakeholder in a community area by adhering to their centralised planning. This study highlights this issue and it is a step towards discovering the sensitivity of integrative and complex problems, especially involving environmental pollution.

Previous researchers have conducted several economic analyses and valuations of the recycling process. Some concluded that the recycling process had the potential to become a significant economic activity that can impact on resource conservation, economic activity, creation of jobs, and reduction in the magnitude of waste disposal problems (Batool et al., 2008). These researchers also conducted economic valuation on the optional recycling process for electronic home appliances (EHA), to identify the formal management framework and gauge the economic feasibility. They concluded that the entire management framework was economically not feasible if waste appliances were taken back from the owners with the current prices unchanged (Liu et al., 2009). Other than that, observations were made of future perspectives on recycling of home appliances, where it was concluded that the recycling fee might reduce incidents of illegal dumping (Aizawa, Yoshida, \& Sakai, 2008).

Numerous studies have been conducted to investigate e-waste recycling, the behaviour of recycling activities, the future prospects of recycling activities, technological options of electronic waste recycling, the effects on the environment, and the current status of e-waste recycling. However, very few studies have sought to analyse the economics of the recycling process and program especially in terms of e-waste recycling (Saphores, Oguseitan, \& Shapiro, 2012; Kang \& Schoenung, 2005; Kuo, 2012; Misra and Pandey, 2005; Li et al., 2011).

Folz (1995), in presenting the analysis of cost and benefits (CBA) of different types of recycling programs, revealed that higher rates of participation and several specific policies and strategies would encourage greater participation in recycling if lower unit recycling costs were imposed. Pickin (2008) argued that the best CBAs were those with range values, disaggregated environmental data, multiple levels of information, sensitivity analysis, and valuation by multiple methods. Further, he suggested that the preference methods may produce valuations that accord with economic theory and which are also more in tune with popular opinion. Other than that, religious communities in environmental practices have played an important role in going beyond the general idealism on the positive influences of religious values or ethics on environmental protection such as recycling (Mohamad et al., 2012). To date, the number of recycling practices has been increasing with several programs having been implemented. However, in order to look at the respondents' responsiveness, a separate study will need to be conducted.

\section{Methods}

Choice modelling $(\mathrm{CM})$, also known as the choice experiment, is a method widely used to estimate the value of a variety of goods or bundles of attributes with an associated price. The CM includes a stated preference technique that frequently provides the identification of the trade-off that each of the consumers make between attributes. For instance, marginal value of changes in each attribute can be generated if individuals would pay one of the attributes to secure the change. In addition, $\mathrm{CM}$ can develop estimates of compensating surpluses for product changes relative to the "business as usual" situation (Bennett \& Blamey, 2001).

This method is based on the characteristic theory of value (Ross Barmish, 1984), where a subject is viewed as being a bundle of component attributes and their levels. Respondents are given a series of question called choice set based on the attributes of the subject. Respondents are then presented with different descriptions of the subject, differentiated in their attributes and levels, and they are asked to rank, and then rate or choose one preferred option from several alternatives (Choi et al., 2010).

Usually, status quo or no action policy will be given as one of the choice options, whilst other change options are designed using variations in the levels taken by constituent characteristics or attributes. With stated preference methods, the valuation context is described in a survey instrument because surveys can describe new goods, limit the choice set, and posit hypothetical markets; they offer possibilities for valuation well beyond those available with revealed preference methods. This method has several clear advantages since it offers a richer data set, benefit transfer potential, context flexibility, strategic bias reduction, and framing effect control (Do \& Bennet. 2007). 
Studies by Cooper et al. (2006) and Karousakis and Birol (2008) are examples of Choice Modeling approach. Both studies applied this method to investigate the waste water preferences and household preferences for curbside recycling service respectively. Basically, respondents were given a series of choice sets, each containing alternative products or services. An alternative comprised a number of attributes, with each attribute assigned with a value, generally referred to as a level.

\subsection{Data Collection and Question Design}

The primary data were collected through conducting in-depth interviews with households in Putrajaya by using stratified random sampling. A total of 600 respondents were interviewed using questions that were formulated based on past studies. The questions were divided into six main sections, namely social and environmental attitudes, awareness of current e-waste disposal options, willingness to participate in recycling scheme, preferences for that scheme, evaluation of Putrajaya's recycling facilities, and householders' current disposal practices. The final section required respondents to provide details of their socio-economic and demographic profiles (Martin et al., 2006). The Likert Scale was used to measure all the environmental attitudes that typically ranged from 1 to 5 . The attributes and levels used in this survey are as illustrated in Table 1.

Table 1. Attributes and Their Levels in the Study

\begin{tabular}{lll}
\hline Attribute/Variable & Attribute Level & Description \\
\hline \multirow{2}{*}{ SPRT } & CM2 & Satisfactory in collection method \\
& CM3 & Good level in collection method \\
ROM & SPRT1 & Wery good level in collection method \\
& SPRT2 & With separation of waste \\
& ROM1 & $3 \%$ in recovery of materials \\
PRICE & ROM3 & $6 \%$ in recovery of materials \\
& PRICE1 & $9 \%$ in recovery of materials \\
& PRICE2 & No additional cost per item purchased \\
& PRICE3 & $5 \%$ additional cost per item purchased \\
& PRICE4 & $7 \%$ additional cost per item purchased \\
\hline
\end{tabular}

Note: Italics text illustrates the status quo/base level

In this study, the model is regressed by including coefficients for each level of the discrete attributes in order to have the best model. Hence, each main attribute is recorded with three columns (CM1, CM2, and CM3) except for SPRT (SPRT1 and SPRT2). For instance, one of the CM attribute levels is coded as 1 if respondents prefer this option among others. It signifies that the particular CM attribute level is selected for changes in services. Level one or status quo is identified as a base level, while level two and level three are identified as medium level and high level respectively. In this situation, variables in the model are regressed to reveal differences in probabilities of option between those in attribute levels and those in base levels.

\section{Results and Discussion}

This section presents the results of the statistical analysis of economic valuation of recycling preferences. The first part of this section provides information on the sociodemographic characteristics of the respondents, such as gender, age, income, education, type of household, and type of residents. The next part subsequently looks at recycling preferences by using choice modelling $(\mathrm{CM})$ analysis.

\subsection{Descriptive Analysis of the Main Attributes}

The descriptive analysis of the attributes are presented in Table 2. For the e-waste service recycling attributes, it is expected that all attributes should be positive, except for the additional cost per item purchased (PRICE). 
Table 2. Descriptive Statistics of Attributes in CM

\begin{tabular}{|c|c|c|c|c|c|c|}
\hline \multirow[b]{2}{*}{ Attribute } & \multirow[b]{2}{*}{ Description } & \multirow[b]{2}{*}{ Frequency $(\%)$} & \multirow[b]{2}{*}{ Mean } & \multirow[b]{2}{*}{ Std. Dev } & \multicolumn{2}{|c|}{ Descriptive Statistics } \\
\hline & & & & & Min & Max \\
\hline \multirow[t]{4}{*}{$\mathrm{CM}$} & Collection Method & & & & & \\
\hline & i) Drop-off & $4200(46.7)$ & & & & \\
\hline & ii) Curbside & $3000(33.3)$ & 1.73 & 0.77 & 1 & 3 \\
\hline & iii) Call-up & $1800(20)$ & & & & \\
\hline \multirow[t]{3}{*}{ SPRT } & Separation & & & & & \\
\hline & i) No & $5400(60)$ & 1.4 & 0.49 & 1 & 2 \\
\hline & ii) Yes & $3600(40)$ & & & & \\
\hline \multirow[t]{4}{*}{$\mathrm{ROM}$} & Recovery of Material & & & & & \\
\hline & i) $3 \%$ & $6000(73.3)$ & & & & \\
\hline & ii) $6 \%$ & $1800(20)$ & 0.4 & 0.02 & 0.03 & 0.09 \\
\hline & iii) $9 \%$ & $600(6.7)$ & & & & \\
\hline \multirow[t]{5}{*}{ PRICE } & $\begin{array}{c}\text { Additional Cost Per Item } \\
\text { Purchased }\end{array}$ & & & & & \\
\hline & i) No Change & $4200(46.7)$ & & & & \\
\hline & ii) $5 \%$ increase & $1200(13.3)$ & & & & \\
\hline & iii) $7 \%$ increase & $1800(20)$ & 0.04 & 0.04 & 0 & 0.1 \\
\hline & iv) $10 \%$ increase & $1800(20)$ & & & & \\
\hline
\end{tabular}

\subsection{The Simple Conditional Logit (CL) Model}

This section presents the analysis of $\mathrm{CM}$ method. Estimation procedures for $\mathrm{CM}$ were completed by using the econometric software LIMDEP, NLogit Version 9. According to a previous study, LIMDEP is most convenient econometric software to estimate conditional logit model even though there are other econometric software that can be used, such as SAS and STATA. The econometric function for a simple CL model can be written as follows:

$$
\mathrm{U}=\beta_{1} \mathrm{X}_{1}+\beta_{2} \mathrm{X}_{2}+\beta_{3} \mathrm{X}_{3}+\beta_{4} \mathrm{X}_{4}+\beta_{5} \mathrm{X}_{5}+\beta_{6} \mathrm{X}_{6}+\varepsilon
$$

Where:

$\mathrm{U}=$ Utility;

$\beta_{1} X_{1}=$ Good level in collection method (CM2);

$\beta_{2} X_{2}=$ Very good level in collection method (CM3);

$\beta_{3} X_{3}=$ With separation of waste (SPRT2);

$\beta_{4} X_{4}=$ Moderate percentage level of recovery materials (ROM2);

$\beta_{5} X_{5}=$ High percentage level of recovery materials (ROM3); and

$\beta_{6} X_{6}=$ Additional cost per item purchased (PRICE).

The aforementioned parameters describe the importance of attributes and their levels in determining consumers' preferences in selecting the best option for improvement in e-waste recycling scheme. The consumers select the best option among the three different options offered which are Recycling Scheme Option 1, Recycling Scheme Option 2, and Current Recycling Scheme/Status Quo. Respondents will choose "status quo" if they do not intend to have any change in recycling scheme, indicating that they are very comfortable with their current situation.

Table 3. Results of CL Simple Model (Model 1)

\begin{tabular}{cccccc}
\hline Variables & Coefficient $(\beta)$ & Std. Error & t-ratio & p-value & Marginal value $(\%)$ \\
\hline CM2 & 0.1703 & 0.0633 & $2.690^{* * *}$ & 0.0072 & 2.1749 \\
CM3 & -0.9802 & 0.1366 & $7.176^{* * *}$ & 0.0000 & -12.5185 \\
SPRT2 & 0.4751 & 0.0736 & $6.455^{* * *}$ & 0.0000 & 6.0677
\end{tabular}




\begin{tabular}{cccccc}
\hline Variables & Coefficient $(\beta)$ & Std. Error & t-ratio & p-value & Marginal value $(\%)$ \\
\hline ROM2 & 1.0117 & 0.1524 & $6.638^{* * *}$ & 0.0000 & 12.9208 \\
ROM3 & -0.8022 & 0.1661 & $0.166^{* * *}$ & 0.0000 & -10.2452 \\
PRICE & -0.0783 & 0.0121 & $0.012^{* * *}$ & 0.0000 & \\
Summary Statistics & & 2400 & & \\
Number of observations & -2342.607 & & \\
Log Likelihood & -2636.669 & & \\
Log Likelihood, No coefficients & 0.11153 & & \\
Pseudo R & & & \\
Adjusted Pseudo R & & & \\
\hline
\end{tabular}

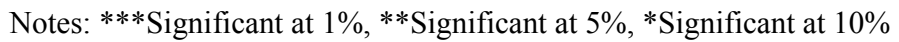

According to Model 1, all the option attribute coefficients are highly significant except for attributes CM3 and ROM3 which are significant with a negative sign. The attributes of CM2 and SPRT2 are significant at the 1\% level with the expected right sign, which specify high positive parameters and are obviously preferable compared to CM1 and SPRT1 (base level). However, the attributes of CM3 and ROM3 had the opposite expected sign (negative). These results indicate that there is no inherent bias towards either the change or no-change options held by the respondents. PRICE is significant at the $1 \%$ level with the expected negative sign. It verifies the hypothesis that increases in additional cost of electronic products brings negative impact on utility. The variable of PRICE has a major impact in WTP and it affects selection of the best price among other prices.

The table shows that the levels of independent variables power are low as described in the model as the Pseudo $\mathrm{R}^{2}$ is 0.1115 (from a minimum value of 0 to a maximum of approximately 1). Gujarati (1999) pointed out that the larger the number of explanatory variables in the model, the higher will be the $\mathrm{R}^{2}$. Nevertheless, the statement should not be taken seriously since the $\mathrm{R}^{2}$ does not take into consideration "degrees of freedom". The marginal rate of substitution (MRS) between other attributes (CM2, CM3, SPRT2, ROM2 and ROM3) and monetary attribute (PRICE) is regressed by using the WALD Test in the LIMDEP software. Thus, the MRS between the attributes can be estimated and the results are reported in the table.

Based on the results for marginal values in Table 3, CM2 has a marginal value of 2.1749. This shows that an improvement in the collection method will result in a marginal value of $2.17 \%$. The marginal value calculated for CM3 is a negative value of -12.5185 , while the SPRT2 has a computed marginal value of $6.07 \%$. Utility increases are indicated by a positive sign in a model. ROM2 has a positive relationship with the calculated marginal value of 12.9208 , which indicates an improvement on recycling service particularly in increasing recovery of materials which have a marginal value of $12.92 \%$. However, the variable ROM3 shows a negative value of $10.25 \%$.

\section{Conclusion}

The present study employed choice modelling method in driving the satisfaction of the recycling service attributes provided. The e-waste recycling service alternatives depend on the decisions made by the respondents. The selected attributes in this study were collection method, separation, and recovery of materials and prices. The survey used conditional logit (CL) model to estimate the marginal values of selected attributes. The alternative attributes should be taken into consideration in designing the provision of recycling service. Further studies are needed to observe the respondents' willingness to pay based on the additional costs for electronic equipment and to gain better understanding of the behaviour of households.

\section{References}

Agarwal, A., Singhmar, A., Kulshrestha, M., \& Mittal, A. K. (2005). Municipal solid waste recycling and associated markets in Delhi, India. Resources Conservation \& Recycling, 44(1), 73-90. https://doi.org/10.1016/j.resconrec.2004.09.007

Aizawa, H., Yoshida, H., \& Sakai, S. (2008). Current results and future perspectives for Japanese recycling of home electrical appliances. Resources Conservation \& Recycling, 52(12), 1399-1410. https://doi.org/10.1016/j.resconrec.2008.07.013

Barmish, B. R. (1984). A new approach to the incorporation of attributes into consumer theory. Journal of Economic Theory, 32(1), 93-110. https://doi.org/10.1016/0022-0531(84)90076-0 
Batool, S. A., Chaudhry, N., \& Majeed, K. (2008). Economic potential of recycling business in Lahore, Pakistan. Waste Management (New York, N.Y.), 28(2), 294-298. https://doi.org/10.1016/j.wasman.2006.12.007

Bennett, J., \& Blamey, R. (2001). The choice Modelling Approach to Environmental Valuation, Cheltenham: Edward Elgar.

Bleiwas, D., \& Kelly, T. (2001). Obsolete Computers, "Gold Mines”, or High-Tech Trach? Resource Recovery from Recycling [R], United States Geological Survey, 7.

Bohm, R. A., Folz, D. H., Kinnaman, T. C., \& Podolsky, M. J. (2010). The costs of municipal waste and recycling programs. Resources, Conservation and Recycling, 55(11), 1051-1059. https://doi.org/10.1016/j.resconrec.2010.01.005

Brekke, K. A., Kverndokk, S., \& Nyborg, K. (2003). An economic model of moral motivation. Journal of Public Economics, 87(9-10), 1967-1983. https://doi.org/10.1016/S0047-2727(01)00222-5

Caplan, A. J., Grijalva, T., \& Jakus, P. (2002). Waste not or want not? A contingent ranking analysis of curbside $\begin{array}{lllll}\text { waste disposal options. } & \text { Ecological }\end{array}$ https://doi.org/10.1016/S0921-8009(02)00210-0

Choi, A. S., Ritchie, B. W., Papandrea, F., \& Bennett, J. (2010). Economic valuation of cultural heritage sites: A choice modeling approach. Tourism Management, 31(2), 213-220. https://doi.org/10.1016/j.tourman.2009.02.014

Chowdhury, M. (2009). Sustainable kerbside recycling in the municipal garbage contract. Waste Management \& Research, 27(10), 988-995. https://doi.org/10.1177/0734242X09335697

Cooper, B., Crase, L., \& Dollery, B. (2006). Using choice modeling to reveal waste water preferences in regional Victoria. Desalination, 188, 31-41. https://doi.org/10.1016/j.desal.2005.04.099

Do, T. N., \& Bennet, J. (2007). Estimating Wetland Biodiversity Values: A choice modeling application in Vietnam's Mekong River Delta (Working Paper EEN0704). Program at Australian National University Economics and Environment Network.

Folz, D. H. (1991). Recycling program design, management, and participation: a national survey of municipal experience. Public Administration Review, 51, 222-231. https://doi.org/10.2307/976946

Folz, D. H. (1995). The Economics of Municipal Recycling: A Preliminary Analysis. Public Administration Quarterly, 19(3), 299-320.

Jenkins, R. R., Martinez, S. A., Palmer, K., \& Podolsky, M. J. (2003). The determinants of household recycling: a material-specific analysis of recycling program features and unit pricing. Journal of Environmental Economics and Management, 45(2), 294-318. https://doi.org/10.1016/S0095-0696(02)00054-2

Kang, H.-Y., \& Schoenung, J. M. (2005). Electronic waste recycling: A review of U.S. infrastructure and technology options. Resources, Conservation and Recycling, 45(4), 368-400. https://doi.org/10.1016/j.resconrec.2005.06.001

Karousakis, K., \& Birol, E. (2008). Investigating household preferences for kerbside recycling services in London: A choice experiment approach. Journal of Environmental Management, 88(4), 1099-1108. https://doi.org/10.1016/j.jenvman.2007.05.015

Kuo, T. C. (2012). Waste electronics and electrical equipment disassembly and recycling using petri net analysis: Considering the economic value and environmental impacts. Computers \& Industrial/ Engineering. In Press, Corrected Proof. https://doi.org/10.1016/j.cie.2011.12.029

Li, B., Dua, H. Z., Ding, H. J., \& Shi, M.Y. (2011). E-Waste Recycling and Related Social Issues in China. Energy Procedia, 5, 2527-2531. https://doi.org/10.1016/j.egypro.2011.03.434

Liu, X., Tanaka, M., \& Matsui, Y. (2009). Economic evaluation of optional recycling process for waste electronic home appliances. Journal of Cleaner Production, 17(1), 53-60. https://doi.org/10.1016/j.jclepro.2008.03.005

Martin, M., Williams, I. D., \& Clark, M. (2006). Social, cultural and structural influences on household waste recycling: A case study. Resources, Conservation and Recycling, 48(4), 357-395. https://doi.org/10.1016/j.resconrec.2005.09.005

Misra, V., \& Pandey, S. D. (2005). Hazardous waste, impact on health and environment for development of better waste management strategies in future India. Environment International, 31(3), 417-431. 
https://doi.org/10.1016/j.envint.2004.08.005

Mohamad, Z. F., Idris, N., Baharuddin, A., Muhammad, A., \& Nik Sulaiman, N. M. (2012). The role of religious community in recycling: Empirical insights from Malaysia. Resources, Conservation and Recycling, 58, 143-151. https://doi.org/10.1016/j.resconrec.2011.09.020

Pickin, J. (2008). Representations of environmental concerns in cost-benefit analyses of solid waste recycling. Resources, Conservation and Recycling, 53(1-2), 79-85. https://doi.org/10.1016/j.resconrec.2008.09.003

Saphores, J.-D. M., Ogunseitan, O. A., \& Shapiro, A. A. (2012). Willingness to engage in a pro-environmental behavior: An analysis of e-waste recycling based on a national survey of U.S. households. Resources, Conservation and Recycling, 60, 49-63. https://doi.org/10.1016/j.resconrec.2011.12.003

Sidique, S. F., Lupi, F., \& Joshi, S. V. (2010). The effects of behavior and attitudes on drop-off recycling $\begin{array}{lllll}\text { activities. Resources, } & \text { Conservation and }\end{array}$ https://doi.org/10.1016/j.resconrec.2009.07.012

Suttibak, S., \& Nitivattananon, V. (2008). Assessment of factors influencing the performance of solid waste recycling programs. Resources, Conservation and Recycling, 53(1-2), 45-56. https://doi.org/10.1016/j.resconrec.2008.09.004

Tiller, K. H., Jakus P. M., \& Park, W. M. (1997). Household Willingness to Pay for Dropoff Recycling. Journal of Agricultural and Resource Economics, 22(2), 310-320.

Timlett, R. E., \& Williams, I. D. (2008). Public participation and recycling performance in England: A comparison of tools for behavior change. Resources, Conservation and Recycling, 52(4), 622-634. https://doi.org/10.1016/j.resconrec.2007.08.003

Wilson, C. D. H., \& Williams, I. D. (2007). Kerbside collection: A case study from the north-west of England. Resources, Conservation and Recycling, 52(2), 381-394. https://doi.org/10.1016/j.resconrec.2007.02.006

\section{Copyrights}

Copyright for this article is retained by the author(s), with first publication rights granted to the journal.

This is an open-access article distributed under the terms and conditions of the Creative Commons Attribution license (http://creativecommons.org/licenses/by/4.0/). 